\title{
Advanced Daylighting evaluation applied to cultural heritage buildings and museums: Application to the cloister of Santa Maria El Paular
}

Santiago Mayorga Pinilla , Daniel Vázquez Moliní1 ${ }^{1}$, Antonio Álvarez Fernández-Balbuena ${ }^{\text {, Gabriel }}$ Hernández Rabosoํㅜ Juan Antonio Herráez 2, Marta Azcutia, Ángel García Botella.

${ }^{1}$ Depto. de Óptica, Facultad de Óptica y Optometría de la Universidad Complutense de Madrid, España.

2 Depto. del Laboratorio de Conservación Preventiva Área del Instituto de Cultura de España.

3 Museo Nacional del Prado, Madrid, España.

${ }^{4}$ Depto. de Física Aplicada a los Recursos Naturales, Universidad Politécnica de Madrid, España.

Corresponding author:

Phone: +34 917758218; fax: +34 913944683 .

E-mail address: smayorga@ucm.es (Santiago Mayorga).

Postal address: Facultad de Óptica y Optometría, c/Arcos de Jalón, s/n, 28037 Madrid, España.

\begin{abstract}
A method to evaluate the risk of using daylight in museums and cultural heritage exhibitions is presented along this study. Although daylight is an ecological and sustainable source of energy and sometimes also an intrinsic part of the artwork, the use of Natural lighting may cause damages in them due to the difficulty of controlling its variability. The developed method quantifies the damage produced to the artworks by daylight compared to artificial light taking into account the level of radiation and its spectral distribution in space and time by comparison with the damage caused by an Illuminant A (Global Risk Factor). The method, applied to the permanent paintings exhibition in the cloister of the fifteenth century of the Monastery of Santa Maria de El Paular, certifies that the control and exploitation of Natural Light should consider an optimal balance between exposure and damage.
\end{abstract}

\section{Keywords:}

Natural Light, risk factor, lighting system, renewable energy, artworks, spectral radiance.

\section{Introduction}

Lighting is one of the most important factors to appreciate the artistic and historical elements but it should be very well controlled since electromagnetic radiation can damage the exposed art material [1]].

The control of light is so far based on certain regulations and guidelines, such as those contained in the CIE 157:2004 [2]]. However, there are spaces in which Natural Light, so difficult to 
control caused by its variability, is the source of illumination, due to the type of construction or to the artistic interest.

The main objective of this work is to obtain a realistic and accurate method to evaluate the impact of Natural Light, as a function of their spatial and temporal location, using calculations involving geometric, photometric and climate aspects of the places where art exhibitions are located. This method makes easier the use of Natural Light as a primary or secondary source and, since it is a renewable energy, the need of artificial light, energy dependence and pollution can be reduced.

In order to evaluate the influence of Natural Light, our research has been developed in a permanent exhibition of 54 oils from Vicente Carducho painter, located in the walls of the fifteenth century cloister of the Monastery of Santa Maria de El Paular in Rascafría (Madrid, Spain).

Section 2 presents an empirical model to evaluate and predict the damage caused by daylight in this cloister. In section 3 the model proposed is applied and validated. Finally, in section 4 discussion and conclusions are presented.

\section{Method for spectral evaluation of daylight damage in artworks}

To date several studies concerning spaces illuminated by Natural Light propose methods to evaluate, use and control this type of illumination, or otherwise to avoid it [ $\underline{3}-\underline{7}]$.

In this research we present a methodology that quantifies the risk factor to which the artworks are exposed (defined and detailed in section 3).

\subsection{Previous}

The cloister of the Monastery was renewed between 2007 and 2011. The purpose of the rehabilitation was to relocate the permanent exhibition removed some years before, due to its deterioration. The Institute of Cultural Heritage of Spain (Ministry of Culture) launched a project to recondition the cloister and to restore the oils previously exposed there. Curators and restorers from the Prado's Museum took over this work.

The project undertook several actions. The Natural Light was controlled through the use of filters installed on the windows. Those filters limit the incident radiation over the paintings, taking into account the cardinal orientation of the cloister corridors. The exhibition was opened to public in 2011.

After the reconditioning of the cloister, the Cultural Heritage Institute asked for the collaboration of the Complutense University of Madrid (UCM), specifically to get a detailed determination of the time and positions where the above work of art could be exposed. This collaboration allowed the managers of the Museum to stablish with objective data the optimal 
locations and dates where the paintings could be exposed. Useful information was provided to the restorers.

The study about the optimal value of radiation exposure on the artworks is based on the above references [8]. The research carried out by the UCM team, has taken into account the recommendations on how artworks should be illuminated $[\underline{9}, \underline{10}]$. The model characterizes the spectral composition of light and its intensity over time and space considering the geographic location of the cloister. The results were used in order to evaluate if the produced damage in the exhibition is under the criteria of conservation of restorer team.

A set of models has been developed to get a realistic measurement of the Natural Light effect on the artworks. The calculation includes a comprehensive and accurate estimation of the time-space variations. Values from the model have been compared with photometric data taken in the cloister along the last six years.

We have also analyzed in the calculation the influence of the responsivity of oil paintings (material used in the works), described by the model of Berlin [11].

According to the protocols on illumination in Museums [12] $U V$ radiation has been neglected by using special glasses with filters placed in the windows whose physical characteristics are described in the following paragraphs. $I R$ radiation was previously monitored and controlled with the temperature conditioning of the cloister. These actions were accomplished in the period of the cloister renewal. So, for the calculations carried out in this paper only radiation from 400 to 780 $\mathrm{nm}$ has been considered, range used by the CIE for the visible radiation.

The installation of glasses with filters of different transmittances (T) to control the radiation level was done by Saint Gobain Company. So, the $U V$ radiation was removed and the visible light controlled. The characteristics of the glasses, according to the cardinal orientation, are specified in Table 1.

Table 1: Characteristics of the glasses previously installed in the cloister windows.

\begin{tabular}{|c|c|c|c|c|}
\hline Orientation & Type Glass & T Visible(\%) & $\mathrm{T} U V(\%)$ & Characteristics \\
\hline NORTH & ST-120 & 13 & $<1$ & SGGCLIMALIT PLUS: \\
\hline SOUTH & ST- 167 & 43 & $<1$ & $\begin{array}{l}\text { Outside glass SGGSTADIP6.5 } 1 \text { PVB SGGCOOL-LITE(ST-_-)/ } \\
\text { translucent VIMAT. Air chamber } 12 \mathrm{~mm} \text {. }\end{array}$ \\
\hline EAST & ST-136 & 24 & $<1$ & Inside glass PLANILUX/ translucent VIMAT $5 \mathrm{~mm}$. \\
\hline WEST & VIMAT & 57 & $<1$ & $\begin{array}{l}\text { SGGCLIMALIT PLUS: } \\
\text { Outside glass SGGSTADIP6.5 } 1 \text { PVB SGGPLANILUX/ translucent } \\
\text { VIMAT. Air chamber } 12 \mathrm{~mm} \text {. Inside glass PLANILUX/ translucent } \\
\text { VIMAT } 5 \mathrm{~mm} \text {. }\end{array}$ \\
\hline
\end{tabular}


The transmittance measurements were taken with a SpectraPro-7501, Meter Triple Grating spectrophotometer Scan Range: 0 to $1400 \mathrm{~nm}$ mechanical range, accuracy: +/- $0.2 \mathrm{~nm}$, Resolution: $0.05 \mathrm{~nm}$ at $435.8 \mathrm{~nm}$.

\subsection{Description of the Models}

In order to obtain an accurate evaluation of daylight it is necessary to define the main parameters which have influence in the final objective. Therefore, the next models have been used:

- Geometric-Photometric simulation.

- Spectral model of Natural Light.

- Spectral Damage model.

- Meteorological model.

The relationships between these models are shown in Fig. 1.

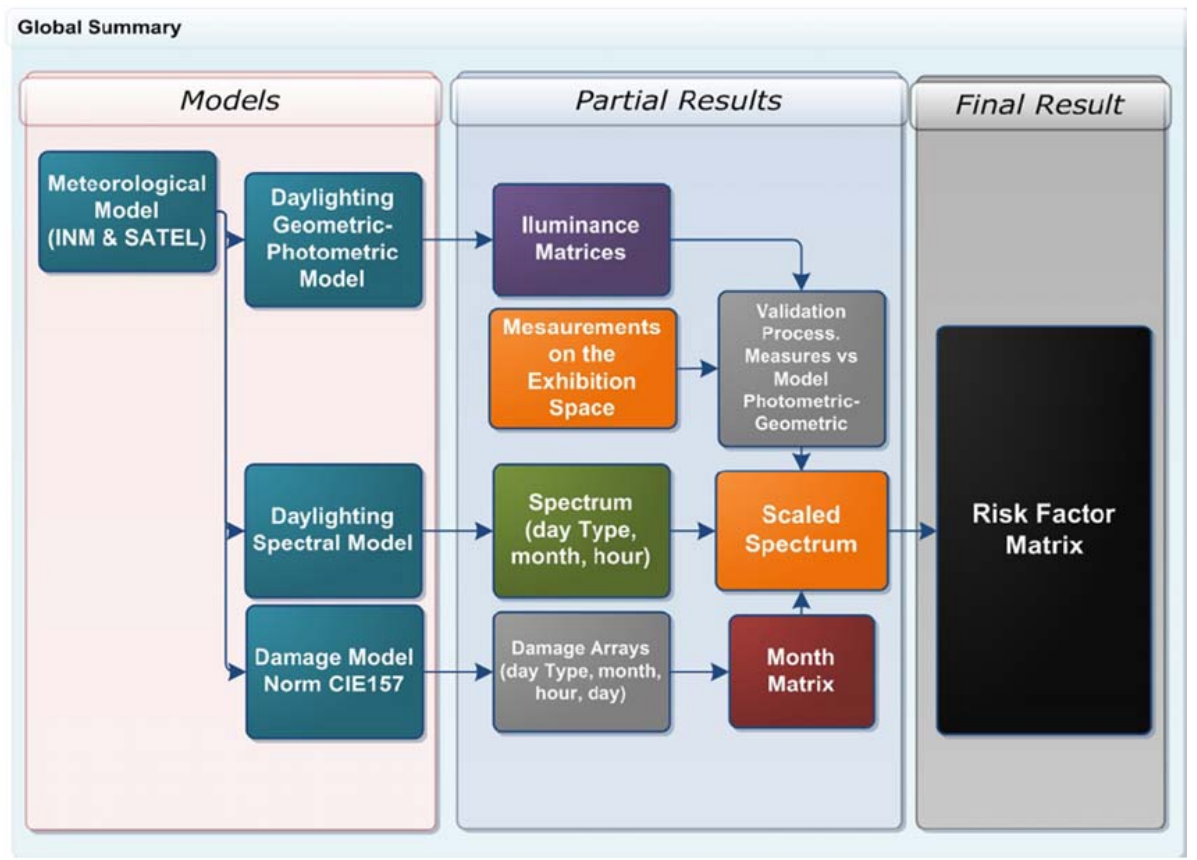

Fig. 1. Organization chart of variables (Models) and partial results to obtain the Risk Factor.

\subsubsection{Geometric-Photometric simulation}

This simulation allows obtaining the illuminance values at each point of the cloister, along the year.

The geometrical part has been developed with a CAD program. This model is applied to specific software processing the photometric characteristics, with Dialux software [13], where the following aspects have been considered:

- Amount of radiation: Natural Light enters, depending on the cardinal orientation and the windows filters, on the located on the walls in front of the oils.

\footnotetext{
${ }^{1}$ http://ridl.cfd.rit.edu/products/manuals/acton/old/MANUAL/Sp-750i.pdf
} 
- Types of day according to the climate: clear day (A; no clouds in the sky), covered day (B; sky foul covered by close) and cloudy day (C; sky partially covered by cloud), and the type of radiation: direct and/or diffuse, according to the data provided by the National Institute of Meteorology AEMET in Rascafría (Madrid) that consider the average percentages of different type of days.

- The study was conducted from January to June, using equivalent illuminance values on 7th and 21th day of each month and at every hour of the day, from sunrise to sunset (more details in the spectral model described in 2.2.2).

- The values of the reflection coefficient used for the surfaces of the cloister, with were measured using a Stellar Net EPP2000² spectrophotometer (Scan Range: 200 to $1100 \mathrm{~nm}$, resolution of the order of $1 \mathrm{~nm}$ ), are: $20 \%$ for the soil, $70 \%$ for the ceiling; and $50 \%$ for the walls.

Since the interest of the study is only the vertical walls where the oils are exposed, only the illuminance values of these surfaces (whose dimensions are approximately $53 \times 6,6$ m) have been used to construct a 200 (horizontal) x 30 (vertical) matrix of equidistant points(distance between each point: $0,26 \mathrm{~m}$ horizontally and $0,22 \mathrm{~m}$ vertically). The sample value has been considered to be good enough for the objective of the research, and does not increase the computational requirements. Any of the matrix values corresponds to the value in Lux of the simulation for the same point.

In order to verify the values of the photometric model, illuminance measurements of the cloister were made using Luxmeter (Lux-Bug Hanwell ${ }^{3}$, Visible wavelength, 400-700 nm, Accuracy, $+/-1 \%$, $U V$ wavelength range Accuracy, $+/-1 \%$ ) placed on the vertical face of the wall, taking a measurement every $15 \mathrm{~min}, 24 \mathrm{~h}$ a day, and every day since 2007 to 2013.

The sensors were placed $3.67 \mathrm{~m}$ above the floor of the cloister in period of the restauration (Fig. 2). This position was chosen because it is the area where Natural Light more affects the paintings. At the same time this height helps to keep safe the sensors of possible interactions with visitors.

Fig. 3 shows the measurements over six months in 2012. 


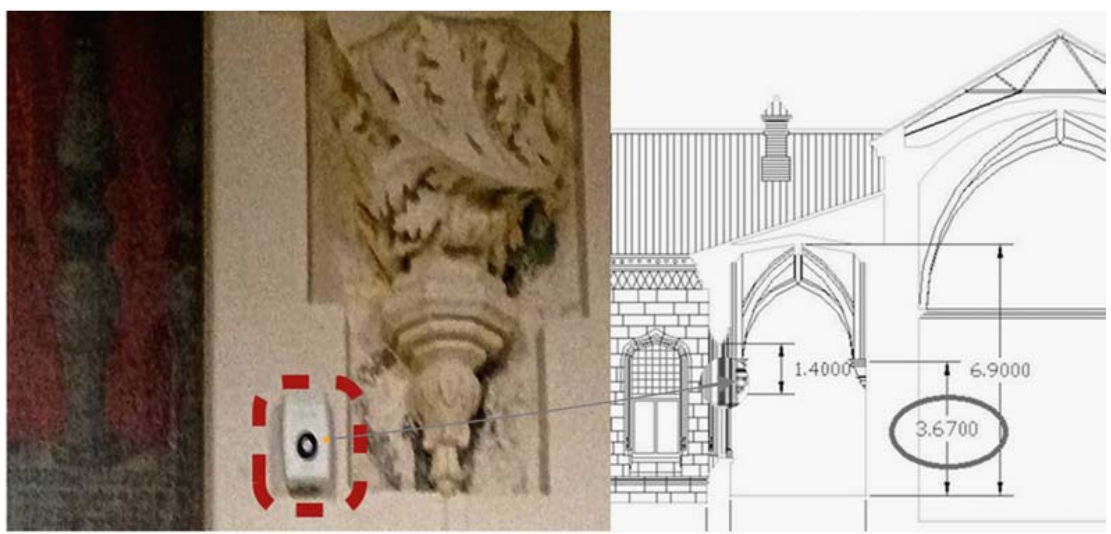

Fig. 2. Situation of the sensors (Luxmeter) placed in the cloister. The arrow indicates the position of the Luxmeter on the wall of the cloister.

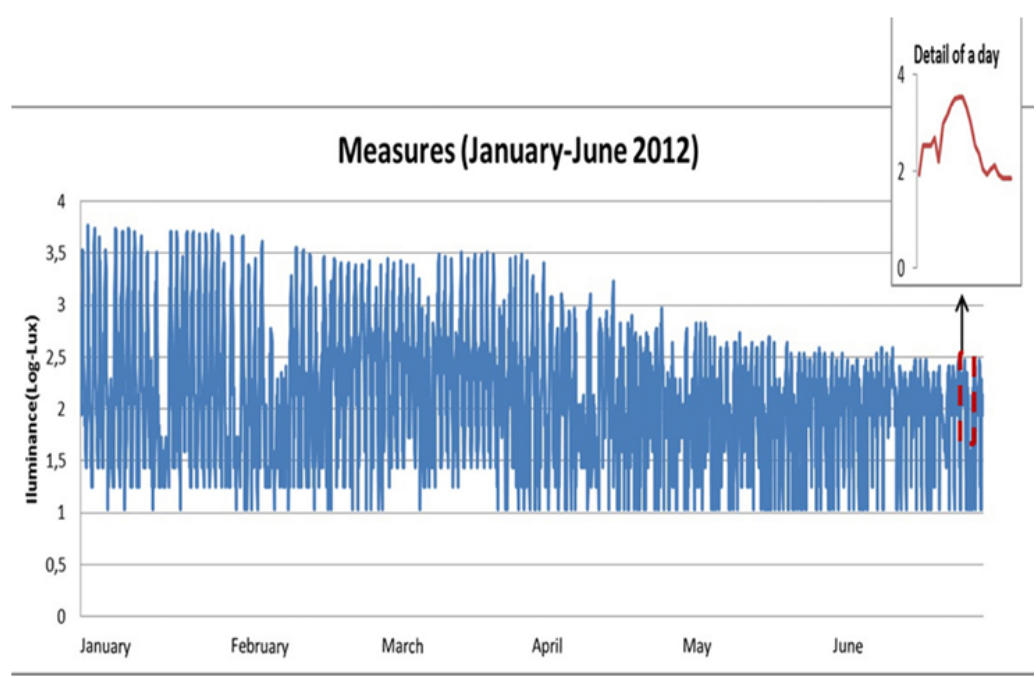

Fig. 3. Illuminance measurements taken with sensor on the west wall of the cloister, from January to June 2012 (illuminance in logarithmic scale). Illuminance detail from June 20th.

\subsubsection{Spectral Model of Natural Light}

The spectral characteristics and the amount of radiation of the Natural Light in Rascafría (Madrid), a very close village to El Paular, have been obtained (Fig. 4). Values of the sun spectral irradiance $E(\lambda)$ in $\mathrm{Wm}^{-2} \mathrm{~nm}^{-1}$ from sunrise to the sunset for each hour of the day and taking into account the characteristics of each month of the year are calculated according to reference models $[14,15]$, following the equation (1).

$$
E(\lambda)=E(\lambda)_{D}+E(\lambda)_{D F}
$$

where $E(\lambda)_{D}$ is the direct irradiance and $E(\lambda)_{D F}$ is the diffuse irradiance in $\mathrm{Wm}^{-2} \mathrm{~nm}^{-1}$.

This model takes into account the latitude, the longitude, the altitude above sea level, and the cardinal orientation, and the factors influencing the atmosphere solar radiation. 
The calculation to know the sun position along the year, from sunrise to sunset, has been made using as a model the following equations described in Ref. [16], for the zone where the Monastery is located, whose latitude and longitude are $40.9^{\circ}$ and $3.7^{\circ}$, respectively.

In the spectral model, the same variables used in the geometric-photometric model were used: type of day (A, B, C), and temporal aspects (month and hour of the day).

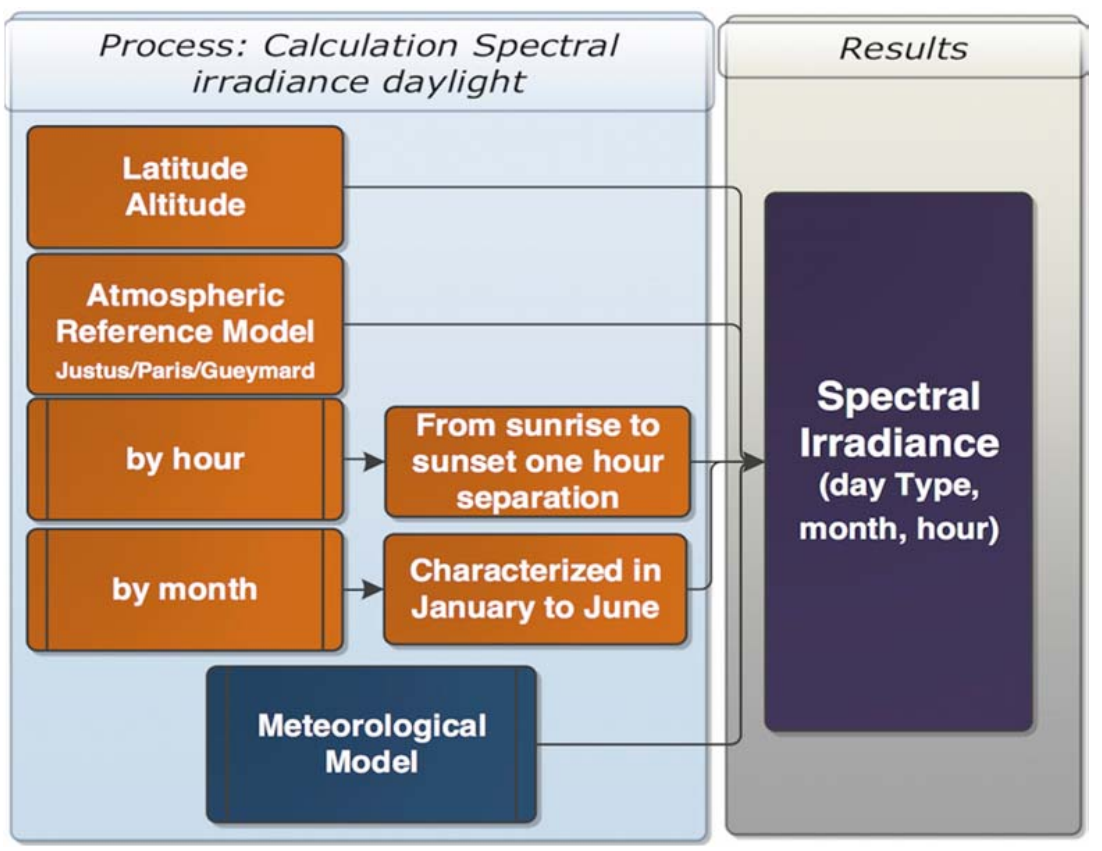

Fig. 4. Diagram of the spectral model of Daylight. Calculation of the spectral irradiance of the radiation from daylight.

\subsubsection{Spectral Damage Model}

The development of this model has been made with reference to the information provided by the standard CIE 157:2004, which describes the scope of the photochemical effect that visible light produces in the exposed oils, and equations for the calculation. Four variables are involved: irradiance, exposure time, spectral distribution of the light source and the nature of the illuminated object. The matrices detailing the final damage (Fig. 5) are obtained from the illuminance matrices calculated in the models above described and using the procedure that follows. Applying these criteria to the Berlin model, we get the exposure threshold of the effective radiance, choosing the material sensitivity (oil in this case) that in the standard has been considered as low sensitivity, and the response is calculated with the exponential relationship in the following equation (2), agreed with reference [2]:

$$
s(\lambda)_{D M, r e l}=\exp [-b(\lambda-300)]
$$


where $s(\lambda)_{D M, \text { rel }}$ defines the relative spectral responsivity on the radiant exposure standard at $300 \mathrm{~nm}$; $b$ is a constant value depending on the sensitivity of the material used in the artworks, where $s(\lambda)$ and $b$ are non-dimensional.

The resulting function $s(\lambda)_{D M, r e l}$, has been applied together with the spectral model $E_{e, \lambda}$, to obtain the effective irradiance $E_{D M}$.

The result is a function of the exposure threshold of effective irradiance of Natural Light for a period of time, and $E_{D M}$ expression (3);

$$
\begin{aligned}
& E_{D M}=\int E_{e, \lambda} s(\lambda)_{D M, r e l} d \lambda \\
& E_{D M} \text { in } \mathrm{Wm}^{-2}
\end{aligned}
$$

To take into account the effective damage, the spectrum of the incident radiation and the relative spectral response of the host material, effective irradiance has to be integrated over time in equation (4),

$$
H_{D M}=\int E_{D M} d t
$$

where $H_{D M}$ is the Effective Radiant Exposure is the effective irradiance over time in $\mathrm{Whm}^{-2}$.

The damage factor $(D M)$ is the value that the effective irradiance exposure takes when obtained for a specific point of the cloister wall in a determined time period, considering the natural illumination conditions above described (geometricphotometric and spectral models of Natural Light). Therefore, in lighting studies applied to cultural heritage, especially in those using Natural Light, it is essential to consider the spectral distribution of radiation, since the damage factor $(D M)$ strongly depends on the wavelength of the radiation []].

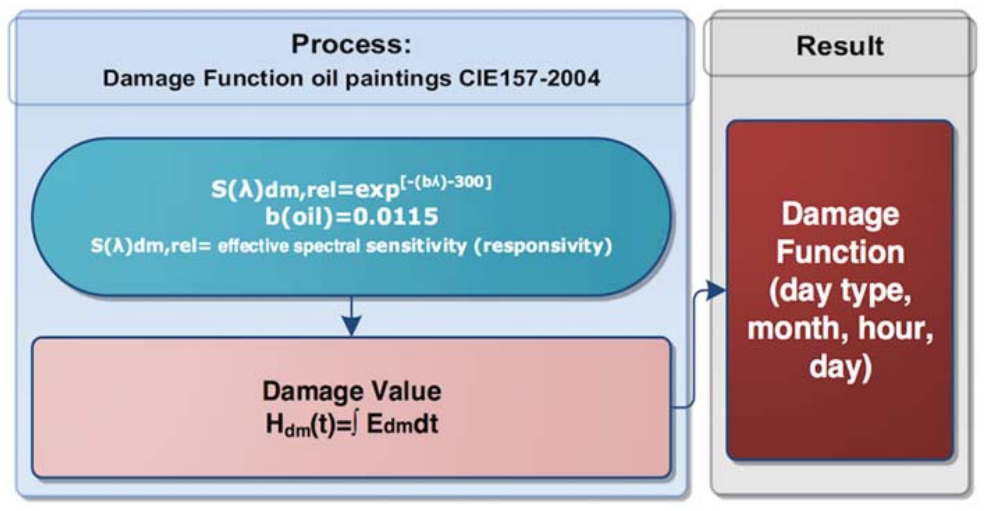

Fig. 5. Diagram of damage function.

$H_{D M}$ provides a value that is an amount of energy per time. In this model a numerical measured standard value is proposed, the Global Risk Factor $(G R F)$, which is the result of the comparison with the illuminant A (incandescent lamp standard) and it is easier to interpret. 
The value obtained for the $G R F_{A}$ indicates how many times the illuminated area exceeds or equals the Illuminant $\mathrm{A}$, being unity for areas having the same $H_{D M}$.

The $G R F_{A}$ parameter serves as a standard measurement. It reports about the possible damage that the artworks in an exhibit with Natural Light would suffer compared to a source of constant illumination pattern. The constant radiation source chosen is an incandescent lamp of 50 Lux (Illuminant A, $H_{D M A}=0.2628 \mathrm{Whm}^{-2}$ ), recommended for sensitive materials under Berlin model [11].

The computing power of the $G R F_{A}$ and its flexibility, make this method to be a very useful tool for restorers and designers of exhibitions, expression (5):

$$
G R F_{A}=H_{D M} / H_{D M A}
$$

To calculate the $G R F_{A}$, it is necessary to integrate properly the above models.

\subsubsection{Meteorological model}

In order to know the amount of radiation of the geographic location of the Monastery (Rascafría, Madrid), it is necessary to estimate the distribution of the different types of days in each month of the year.

We have analyzed statistical values from the National Institute of Meteorology (AEMET) and Satel satellite $[\underline{17}, 18]$. (Fig. 6) These data provide the frequency at which the three day types (A, B, C; for description see above).

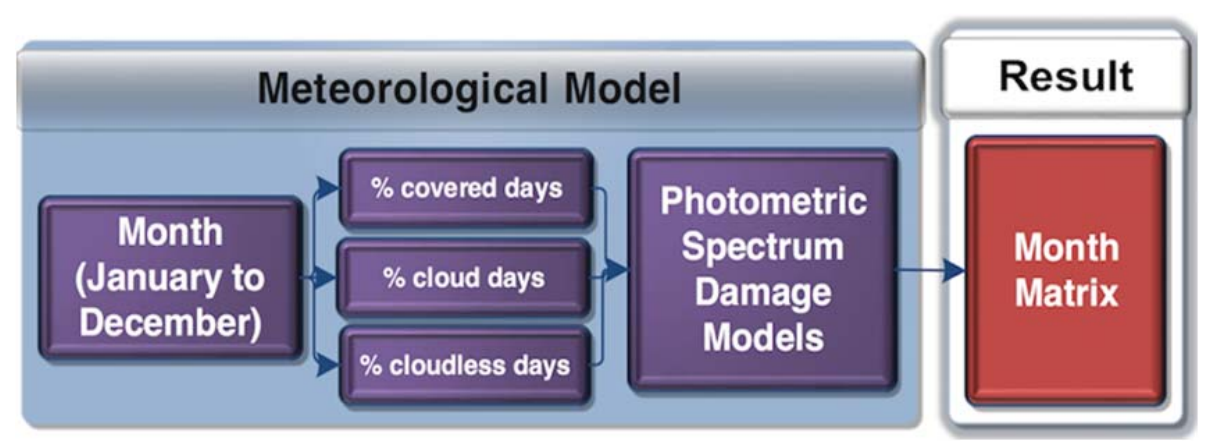

Fig. 6. Meteorological model diagram.

\section{Results: Application to the cloister of Santa Maria de El Paular}

\subsection{Results Geometric Photometric Model}

Fig. 7 shows the illuminance distribution on March 7 at 10 am for a clear day. It is shown that South and West walls are the areas receiving the greatest radiation in this hour and in this day, being the North wall the least radiated.

- Correspondence between measured and calculated values in Geometric-Photometric model 
The illuminance values measured during period 2007-2013 have been compared to the values obtained using the photometric model. In order to clearly visualize the correlation between the two series of measurements, mean values of both data sets have been calculated daily. For this purpose we have used the value of the photometric model that matches the position of the Luxmeter.

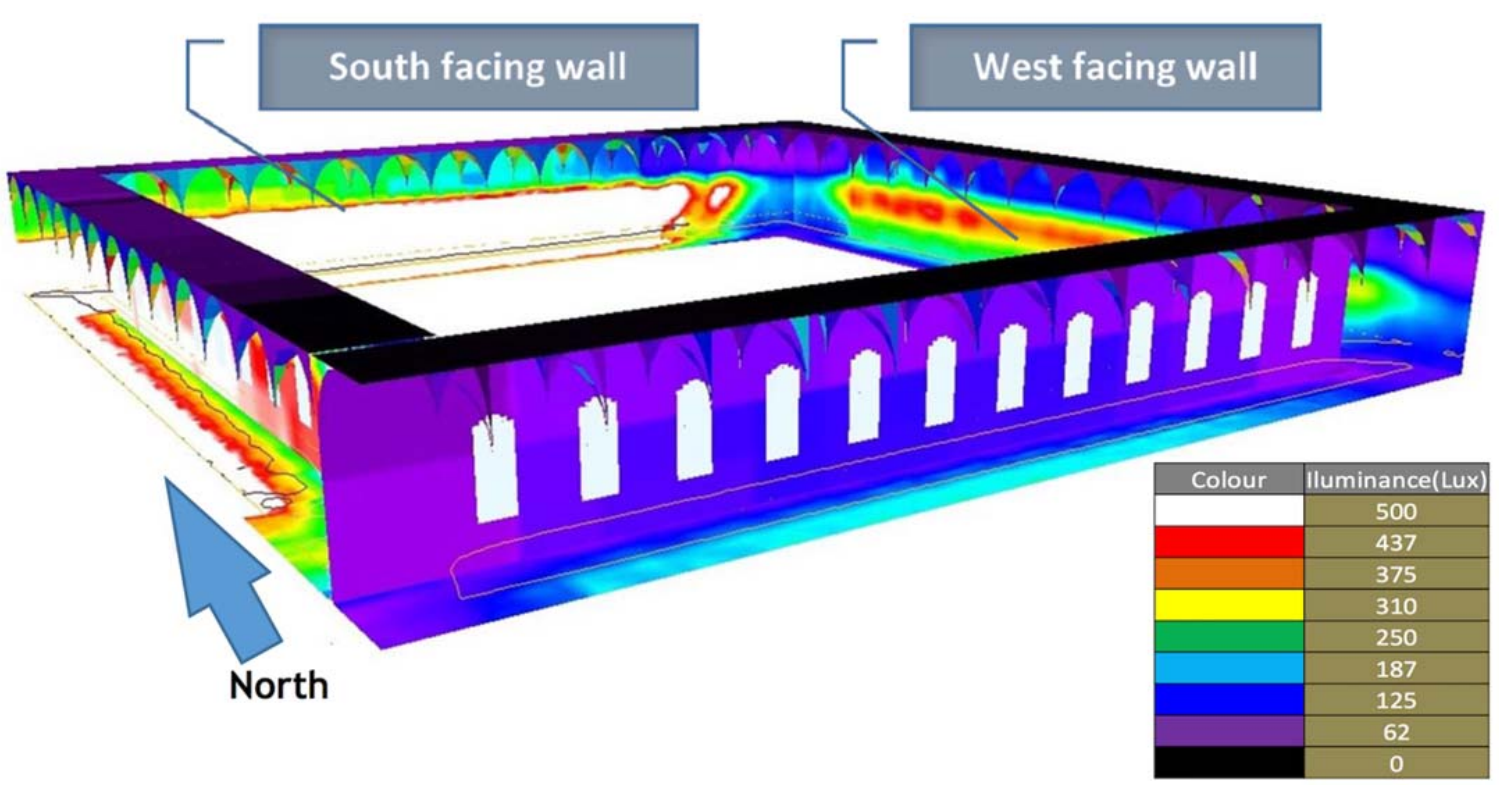

Fig. 7. Simulation of the cloister illumination with Dialux. This is the Natural Light of a cloudless day in March at $10 \mathrm{am}$. The illuminance of the cloister is shown in false color. The oils are placed walls marked (West facing wall and South facing wall). The lux value of each color is shown in the table of the Figure.

As an example, Fig. 3 shows the variation of the data measured by one of the Luxmeter installed in the West wall. Any of the peaks corresponds to the daily illuminance variation, as can be seen in the inset of this Figure referred to June 20th. To test the model, we have compared the illuminance data measured in each corridor wall with those calculated using the model proposed in section 2.2.1. The fitting of the theoretical model to the measured data is good enough (in the worst situation, East wall, an error less than 6\% is found) (Fig. 8), since the average error is less than 5\%.

\subsection{Results from the Natural Light Spectral Model}

The radiation spectral distribution for each type of day (clear, covered and cloudy) and the solar position have been calculated. Fig. 9 shows an example for May 21st on a clear day from sunrise to sunset. 


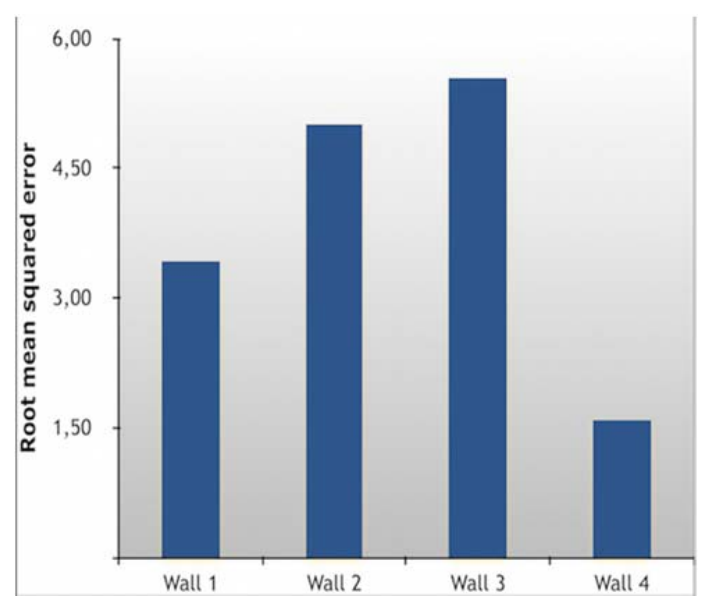

Fig. 8. Comparison of Measured values with values obtained by the simulation program in Lux hour/Month.

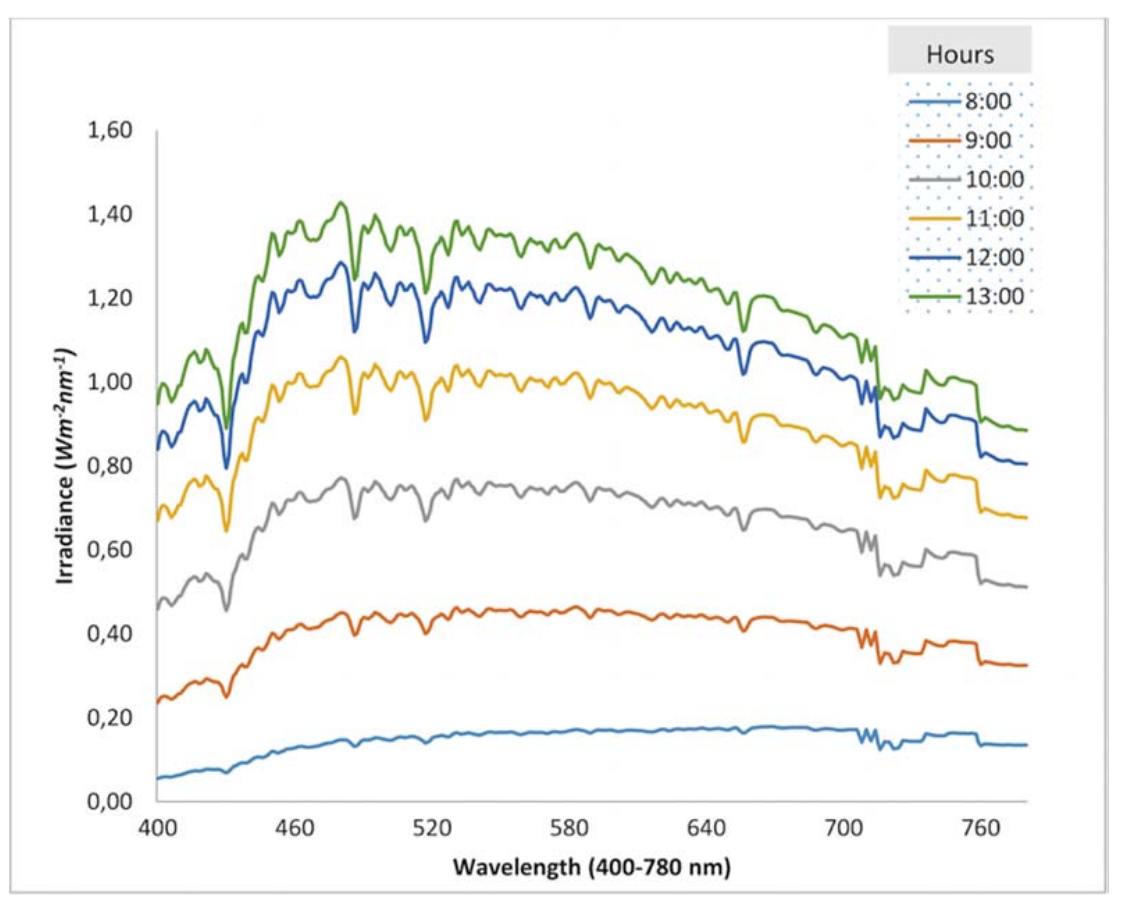

Fig. 9. May 21st spectral curves, from sunrise to zenith, on a clear day. Spectral range covers 400-780 $\mathrm{nm}$ in wavelength, Irradiance in $\mathrm{Wm}^{-2} \mathrm{~nm}^{-1}$.

\subsection{Effective damage on the vertical walls}

The results determine the $H_{D M}$ value, corresponding to the different walls of the cloister, divided into arrays of $200 \times 30$ points. This model allows deriving the $H_{D M}$ for different areas and periods of the year. Although in general, values do not exceed the CIE 157:2004 recommendations, which for low responsivity are set to $850 \mathrm{Whm}^{-2}$, analyzing each point of the walls, areas in which this value is far exceeded are found, since they are more exposed to direct sunlight. Fig. 10(a) shows the evolution in time (from January to June) of the maximum values of $H_{D M}$ choosing areas that receive more radiation on each wall. Fig. 10(b) presents the maximum accumulated value of $H_{D M}$ for the same points of each wall (in both figures, units of $\mathrm{Whm}^{-2}$ ). 


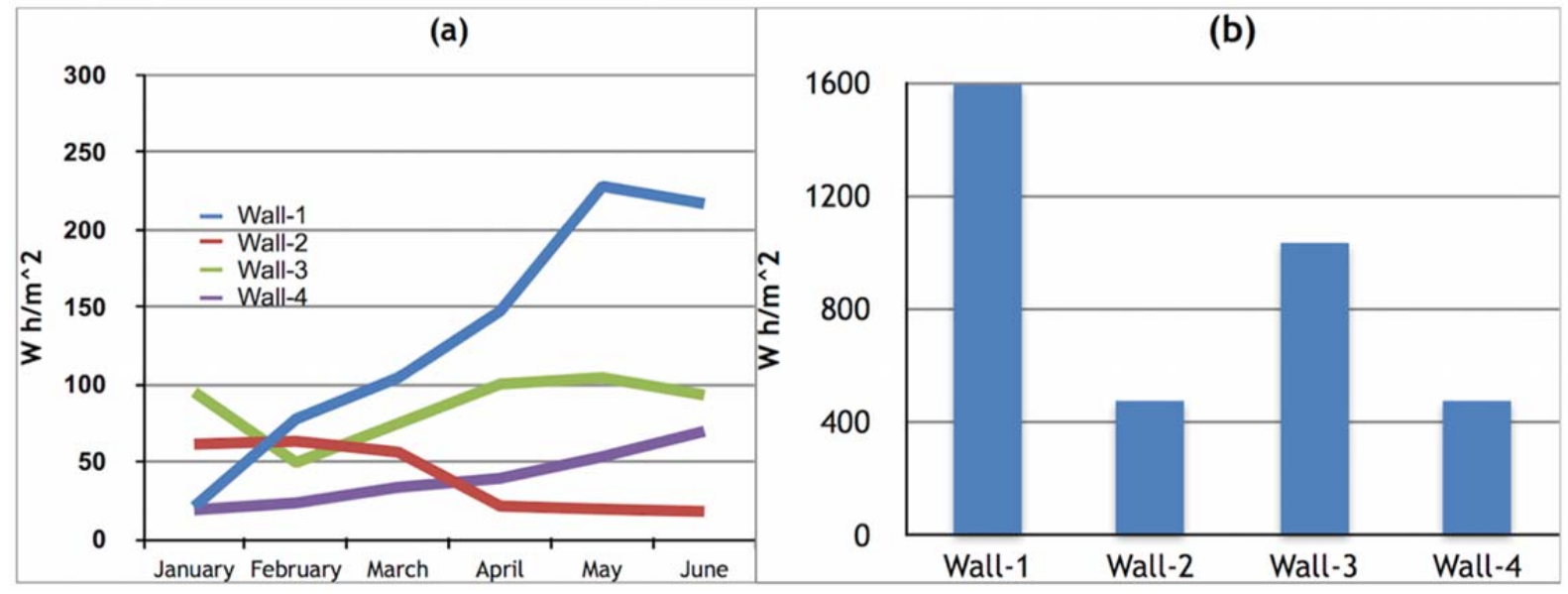

Fig. 10. (a) Maximum values of $H_{D M}$ of each wall of the cloister, as the Berlin model of the standard CIE 157:2004. Vertical axis represents the average values of $H_{D M}\left(W h m^{-2}\right)$. (b) Maximum annual aggregate value of $H_{D M}$ for the points in the walls receiving more radiation.

\subsection{Spectrum and Radiance effective Standard filament lamp (Illuminant A)}

To make the information more easily understandable we have made a comparison with an Illuminant A, in the spectral range 400-780 nm (Fig. 11).

\subsection{Meteorological Model}

The frequency of each of the three types of days (A, B, C) is showed in Fig. 12.

\subsection{Global Risk Factor $\left(G R F_{A}\right)$}

Fig. 13 represents the accumulated $G R F_{A}$ for six months in the walls 1 (West facing) and 4 (South facing) of the cloister.

The information contained in this figure allows the people responsible of maintaining the cloister to appreciate how the radiation acts in each area and each month. In some parts of the West wall, the accumulated value of $G R F_{A}$ over six months is 150 (Fig. 13(b)). If this $G R F_{A}$ is considered as a high value, it is possible either to reduce the transmittance of the filter window or to generate mechanisms to protect the most exposed areas in the concrete hours and months with more incident radiation. 


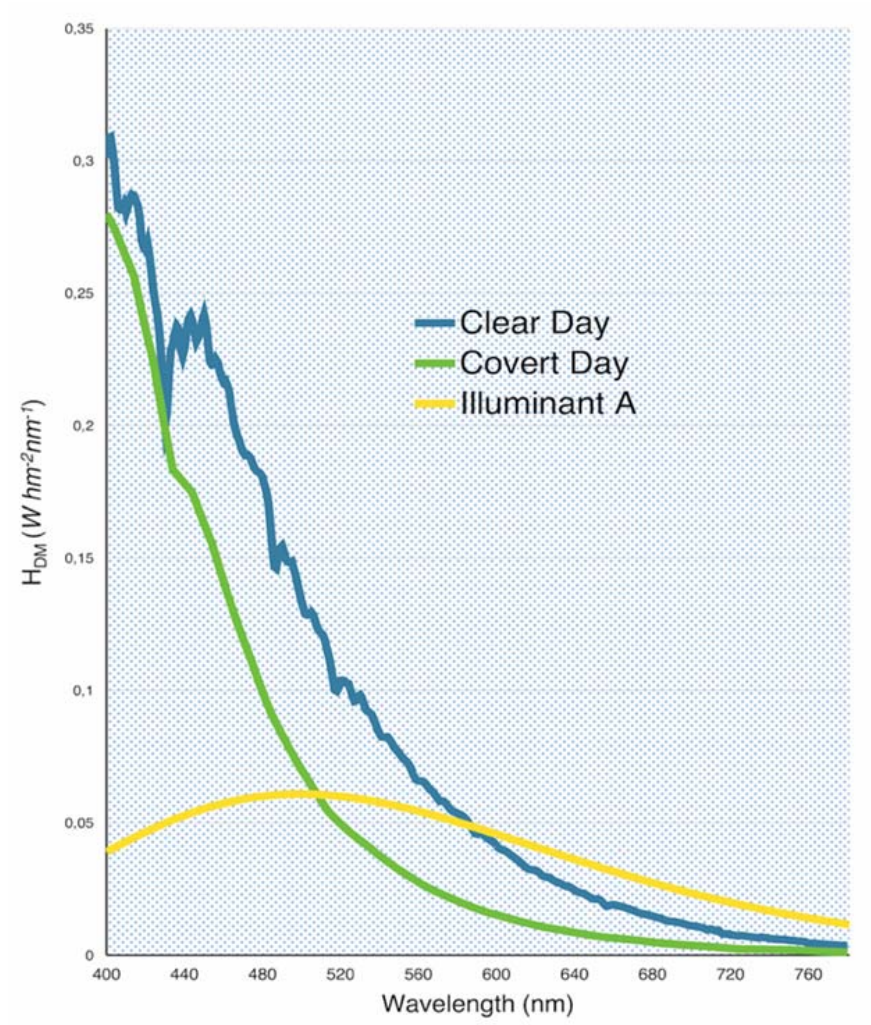

Fig. 11. Comparison between relative oil responsivity, $s(\lambda)$ and $H_{D M}$ Illuminant $A$ (yellow), Natural Light in May 21 (blue), and covered day (green). x axis: $\mathrm{nm}$, y axis: $H_{D M}\left(W h m^{-2} \mathrm{~nm}^{-1}\right)$.

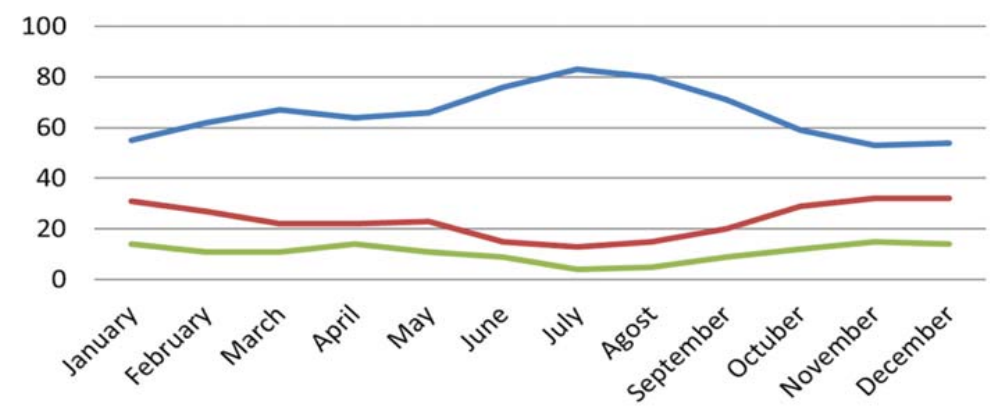

Fig. 12. Percentage of each type of day in Madrid according to SATEL database. Blue: \% clear day, Red: \% cloudy day, Green: \% covered day.

The study can be applied for each art work, every space, every hour, every month. Information is collected with the aim of making more efficient the use of Natural Light as a renewable energy in that place.

Artworks on the West wall have a highest $G R F_{A}$ respect to the other walls. However, regions receiving more radiation on the wall 4 (East) have a $G R F_{A}$ lower, less than 80 . This is half the maximum value obtained in the West wall, and the monthly average of the maximum values accumulated in the walls 2 (North) and 4 (South) are 40 and 60 respectively. 


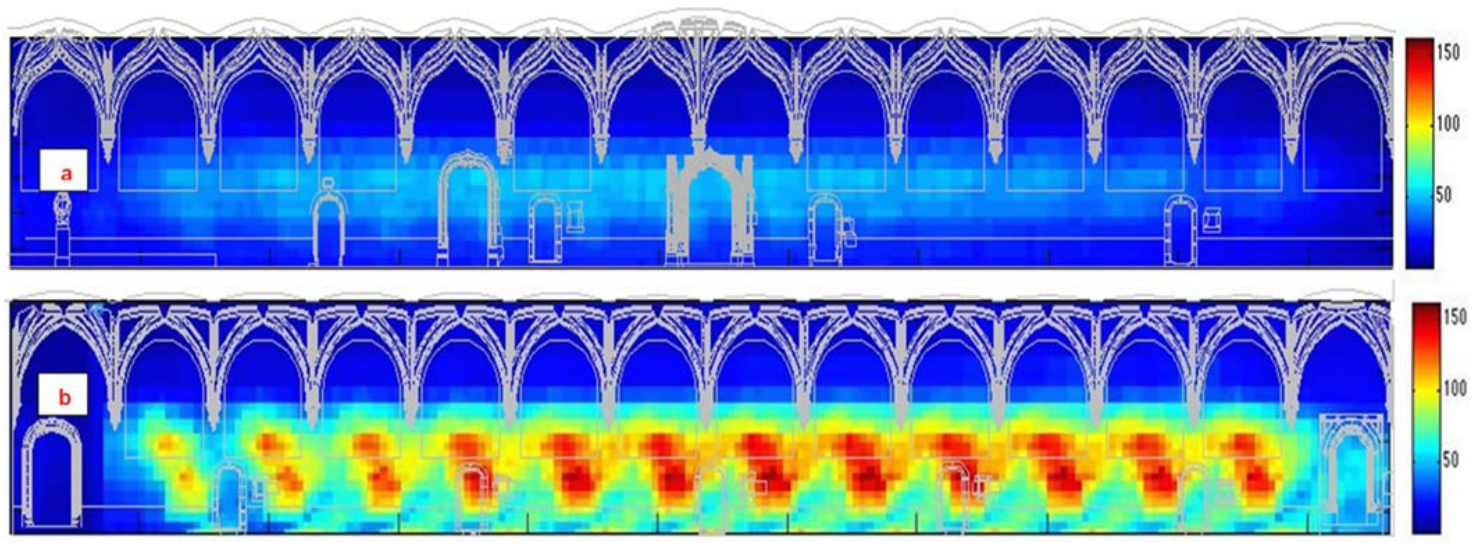

Fig. 13. Values of $G R F_{A}$ on the South (a) and West (b) walls of the cloister from January to June compared with incandescent lamp 50 Lux.

The study advises against the use of wall areas reaching a $G R F_{A}$ value of 150 . The average value of $G R F_{A}$ where the pictures are located is 80 , which can be considered as an acceptable value. Preventively artworks located in areas where $G R F_{A}$ is higher, are being monitored for eventual damages.

\section{Discussions and Conclusions}

Daylight is very often an essential part in the exhibition of artworks; either because its use has been considered inevitable or because it is an essential part of the work of art itself, as in the case studied in the present work.

The advantages of the use of Natural Lighting in architecture are widely accepted (energy saving, not polluting, renewable source, psychological comfort, circadian cycle, colour reproduction). However, its application in museums has been long disputed due primarily to the difficulty of controlling and evaluating it properly.

The detailed and precise analysis carried out in this study can be used to obtain reliable values of the risk that makes the use of the daylight an optimal source of lighting applying a reasonable and noncomplex methodology.

The calculation system applies Natural Light spectral distribution to evaluate the impact (relative damage) on each area of the artwork, taking into account the level of radiation estimated at every point and every moment. It will be also necessary to calculate if this value is relevant enough or if it would be more convenient to relocate the artworks, or to use filters with more protection.

It is necessary to use the spectral information when calculating the relative damage of Natural Lighting. The obtained values are different to those obtained when we only analyze the illuminance, since the spectral distribution of the daylight changes substantially depending on time, type of day and the orientation of the studied point. 
The possibility of having spatiotemporal damage maps provides to exhibition managers an indispensable tool that could define the policy of the artworks exhibition (right location and the time when they can be exhibited).

Finally, $G R F_{A}$ allows taking decisions about the convenience of exhibiting certain kinds of artworks, and to consider not only the spatial distribution of the pieces, but also the periods of time when they have to be exhibited. In areas of high radiation, pieces with low sensitivity can be displayed the whole year, or alternatively it is possible to select periods of time when the $G R F_{A}$ is lower to display the most light-sensible works. For the latter case, since this cloister is located in a very touristic area with visitor mainly in summer, one could think of exhibiting these sensitive works in more protected areas in summer time. Areas with lower $G R F_{A}$ would be the most convenient to exhibit the artworks permanently.

\section{Acknowledgment}

This work has been supported by HAR 2012-31929. 


\section{Bibliography}

[1] C. Cuttle, Damage the museum objects due to light exposure, Light. Res. Technol. 28 (1) (1996) 1-9.

[2] International Commission on Illumination, Control of Damage to Museum Objects by Optical Radiation, CIE Publication 157, CIE, Vienna, 2004, ISBN 9783901906275.

[3] J. Del Hoyo-Melendez, An evaluation of daylight distribution as an initial preventive conservation measure at two Smithsonian Institution Museums, Washington DC, USA, J. Cult. Herit. 12 (2011) 54-64, http://dx.doi.org/ 10.1016/j.culher.2010.05.003.

[4] C. Balocco, E. Frangioni, Natural Lighting in the Hall of Two Hundred. A pro- posal for exhibition of its ancient tapestries, J. Cult. Herit. 11 (2010) 113-118.

[5] C. Balocco, R. Calzolari, Natural Light design for an ancient building: a case study, J. Cult. Herit. 9 (2008) 172-178.

[6] T. De Graaf, Sustainable lighting of museum buildings, Renew. Energy (2014), http://dx.doi.org/10.1016/j.renene.2013.11.035.

[7] M. Wilson, Lighting in museums: lighting interventions during the European demonstration project, Energy Effic. Sustain. Retrofit. New Mus. Build. (NNES- 1999-20) 25 (No. 3-4) (2006) 153-169, http://dx.doi.org/10.1080/ 14786450600921546.

[8] S. Michalski, The Lighting Decision. In, Fabric of an Exhibition Preprints of Textile Symposium 97, Canadian Conservation Institute, Ottawa, 1997, pp. 97-104.

[9] D. Saunders, J. Kirby, Wavelength dependent fading of artists pigments, in: International Institute for Conservation of Historic and Artistic Works, 1994, pp. 190-194.

[10] P. Iacomussi, G. Rossi, Influence of visible radiation on radiometric properties of paints, Surf. Eng. 24 (2) (2008) 90-97. http://dx.doi.org/10.1179/174329408X298120

[11] G. Hilbert, Zur Beleuchtung musealer exponate, Restauro 5 (1991) 313-321.

[12] Lighting Research Center, Museum lighting protocol project, Archeol. Collect. Ser. (1998) 138. http://ncptt.nps.gov/wp-content/uploads/1998-31.pdf.

[13] DIALux, 2014. Retrieved from, www.dial.de/DIAL/es/dialux.html.

[14] C. Justus, M. Paris, A model for solar spectral irradiance and radiance at the bottom and top of a cloudless atmosphere, J. Clim. Appl. Meteorology 24 (1984) 193-205.

[15] C. Gueymard, Parameterized model for direct beam and transmittance, Sol. Energy 71 (5) (2001) 325-346.

[16] D. Myers, Solar Radiation: Practical Modeling for Renewable Energy Appli- cations, CRC Press, Boca Raton, FL, 2013, 13:978-1-4665-0294-9. 
[17] Web Information Meteorological Institute of Spain. Retrieved 10 May 2013, from http://www.aemet.es/es/portada.

[18] Web information Satel. Retrieved 10 May 2013, from http://www.satel-light. com/indexeS.htm. 